Check for updates

Cite this: Nanoscale Adv., 2019, 1, 3400

Received 25th June 2019 Accepted 29th July 2019

DOI: $10.1039 / c 9 n a 00401 g$

rsc.li/nanoscale-advances

\section{One-pot synthesis of a new generation of hybrid bisphosphonate polyoxometalate gold nanoparticles as antibiofilm agents $\dagger$}

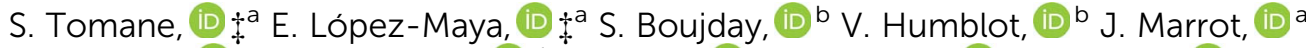 \\ N. Rabasso, (iD c J. Castells-Gil, (iD d C. Sicard, (D) ${ }^{\mathrm{c}}$ A. Dolbecq, (iD) ${ }^{a}$ P. Mialane (D) \\ and $A$. Vallée (iD *a
}

A reduced polyoxovanadate functionalized with bisphosphonate molecules was synthesized and used to prepare in one step hybrid organic-inorganic polyoxometalate decorated gold nanoparticles. These new composites were shown to strongly inhibit $P$. aeruginosa and $S$. epidermidis biofilm growth, with the three components constituting the nanoparticles ( $\mathrm{Au}^{0}$ core, vanadium and alendronate) acting synergistically.

Nowadays, the wide use of antibiotics has led to the emergence of resistant bacteria causing serious public health problems. Antibiotic resistance currently includes all known classes of natural and synthetic compounds leading to an urgent requirement for alternatives. ${ }^{1}$ Among the different resistance mechanisms developed by bacteria, some bacterial populations use cell attachment to solid substrates forming associations named biofilms. ${ }^{2}$ Particularly, bacterial biofilms are much more resistant to antibiotics than planktonic cells because of the generation of extracellular polymeric substances, which impede the penetration of antibacterial agents that reduce the growth rates of the biofilm cells, impacting the effectiveness of antibiotics capable of targeting rapidly multiplying cells., ${ }^{3,4}$ Recently, the use of antimicrobial nanomaterials has attracted great attention because of their ability to disrupt the bacterial membranes and to hinder biofilm formation. ${ }^{5,6}$ Several nanomaterials, such as silver, copper and zinc oxide nanoparticles (NPs), exhibit intrinsic

anstitut Lavoisier de Versailles, UVSQ, UMR CNRS 8180, Université Paris-Saclay, 45, avenue des Etats-Unis, 78035 Versailles Cedex, France. E-mail: anne.vallee@uvsq.fr ${ }^{b}$ Sorbonne Université, Laboratoire de Réactivité de Surface (LRS), UMR CNRS 7197, 4 place Jussieu, 75252 Paris, France

'Institut de Chimie Moléculaire et des Matériaux d'Orsay, UMR CNRS 8182, Université Paris-Sud, Université Paris Saclay, 15 rue Georges Clemenceau, 91405 Orsay Cedex, France

${ }^{d}$ Universidad de Valencia (ICMol), Catedrático José Beltrán-2, 46980, Paterna, Spain $\dagger$ Electronic supplementary information (ESI) available: Experimental details, TGA and IR spectra, the effect of concentration on biofilm formation. See DOI: 10.1039/c9na00401g

\$ These authors contributed equally to this work. antibacterial activity. ${ }^{\mathbf{1}}$ Nevertheless, their toxicity remains problematic. In contrast, it has been evidenced that gold nanoparticles (AuNPs) are non-toxic, ${ }^{7-9}$ and in the last decade conjugates of AuNPs with antibiotics ${ }^{\mathbf{1 0}-\mathbf{1 4}}$ or other antibacterial agents ${ }^{15-19}$ have been shown to improve antibacterial activity against biofilms. Besides, several polyoxometalates (POMs), which can be seen as negatively charged molecular oxides incorporating metals (mainly tungsten, molybdenum and vanadium) in high oxidation states, ${ }^{\mathbf{2 0}}$ have shown important antibacterial activity, ${ }^{21-26}$ and notably two examples of antibiofilm POM composites have been reported in the literature..$^{27,28}$ In this context, the use of POMs as active antibacterial agents supported by AuNPs represents a promising alternative. The relevance of this approach to the elaboration of antibacterial agents is supported by the studies of Daima et al., which showed that AuNPs post-functionalized with purely inorganic commercial POMs exhibit antibacterial activity against the non-resistant $E$. coli bacteria. ${ }^{29,30}$ In addition, precedent studies have established that POMs containing $\mathrm{Mo}^{\mathrm{V}}$ or $\mathrm{V}^{\mathrm{IV}}$ ions can be used as reducing agents for the synthesis of a large variety of POM functionalized metallic NPs. Importantly, AuNPs consisting of a metallic core stabilized by POMs in their oxidized form have been obtained in one step, at room temperature and in water. ${ }^{31-33}$ This synthetic strategy has, however, only been exploited for purely inorganic reduced POMs, while the use of reduced hybrid organic-inorganic polyoxometalates could lead to antibacterial materials combining the properties of AuNPs, POMs and biologically active organic substrates. The chemistry of POMs structured by bisphosphonate ligands (BPs) has been widely studied, ${ }^{\mathbf{3 4 - 4 0}}$ and in particular several molybdenum, tungsten and vanadium complexes incorporating the alendronate (Ale) ligand $\left[\mathrm{O}_{3} \mathrm{PC}\left(\mathrm{C}_{3} \mathrm{H}_{6} \mathrm{NH}_{3}\right) \mathrm{OPO}_{3}\right]^{4-}$ have been obtained. ${ }^{20,41}$ Interestingly, it has also been shown that alendronate itself increases antibiofilm effects when combined with bioactive glass. ${ }^{\mathbf{4 2}}$ Considering inorganic POMs, it has been evidenced that compounds incorporating vanadium centers exhibit the highest antibacterial activities. ${ }^{19}$ It follows that the study of the 
antibacterial properties of systems combining alendronate molecules, POMs containing vanadium ions and AuNPs appears to be particularly attractive.

Herein, we report on the inhibition of Gram-negative and Gram-positive bacteria biofilm growth by such composites. A reduced polyoxovanadate $\left(\mathrm{POV}_{\text {red }}\right)$ functionalized with alendronate ligands was first synthesized. Then, the ability of this reduced $\mathrm{POV}_{\text {red }}$ to act as both a reducing and stabilizing agent was exploited $^{32,43}$ to prepare in one step alendronate POV capped gold NPs (NPs@POV). In parallel, citrate-stabilized gold nanoparticles (CitNPs) functionalized with hybrid POVs in their reduced form were prepared for comparison of the activities of the two systems (Scheme 1). Finally the antibacterial properties of these new NPs@POV hybrid materials toward biofilm formation by Pseudomonas aeruginosa and Staphylococcus epidermidis were studied. To the best of our knowledge, this work represents the first investigation of materials associating NPs, POMs and biologically active organic substrates for antibiofilm applications.

\section{Results and discussion}

\section{Polyoxovanadate and nanoparticle synthesis and characterization}

First, a reduced polyoxovanadate $\left(\mathrm{V}_{3}(\mathrm{Ale})_{3}\right.$, also called here $\left.\mathrm{POV}_{\text {red }}\right)$ was synthesized by mixing sodium metavanadate and alendronic acid at $\mathrm{pH} 4.7$ in water. In this synthesis, the $\mathrm{V}^{\mathrm{V}}$ ions are likely reduced by triethylamine which is added in the medium to increase the $\mathrm{pH}$ (see the Experimental section, ESI $\dagger$ ). Despite numerous efforts, only low quality single-crystals were obtained. However, data collection at the synchrotron allowed solving the structure of the synthesized compound. In the structure of $\mathrm{POV}_{\text {red, }}$ two independent molecules are in the asymmetric unit, which only differ by the position of the alkyl chain of one of the alendronate ligands (Fig. 1 and S1, ESI $\dagger$ ). Xray diffraction studies thus evidence the formation of the title complex $\quad \mathrm{Na}_{3}\left[\mathrm{~V}_{3} \mathrm{O}_{3}\left(\mathrm{H}_{2} \mathrm{O}\right)\left(\mathrm{O}_{3} \mathrm{PC}\left(\mathrm{C}_{3} \mathrm{H}_{6} \mathrm{NH}_{3}\right)(\mathrm{OH}) \mathrm{PO}_{3}\right)_{3}\right] \cdot 10 \mathrm{H}_{2} \mathrm{O}$ $\left(\mathrm{V}_{3}(\mathrm{Ale})_{3}\right)$. This $\mathrm{POV}_{\text {red }}$ is reminiscent of the zoledronate compound $\quad \mathrm{Na}_{3}\left[\mathrm{~V}_{3} \mathrm{O}_{3}\left(\mathrm{H}_{2} \mathrm{O}\right)\left(\mathrm{O}_{3} \mathrm{PC}\left(\mathrm{C}_{4} \mathrm{H}_{6} \mathrm{~N}_{2}\right)(\mathrm{OH}) \mathrm{PO}_{3}\right)_{3}\right] \cdot 12 \mathrm{H}_{2} \mathrm{O}$

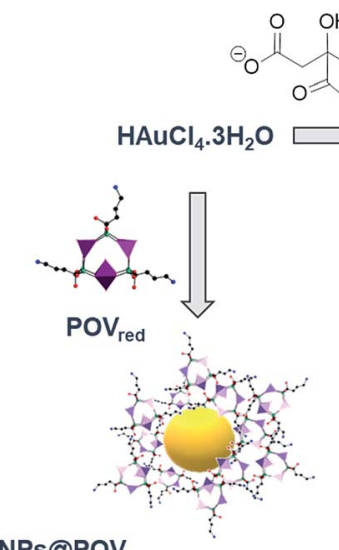

NPs@POV

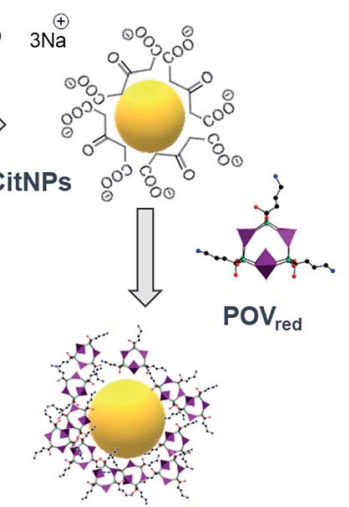

CitNPs@POV

Scheme 1 Schematic representation of CitNPs, CitNPs@POV $V_{\text {red }}$ and NPs@POV synthesis.

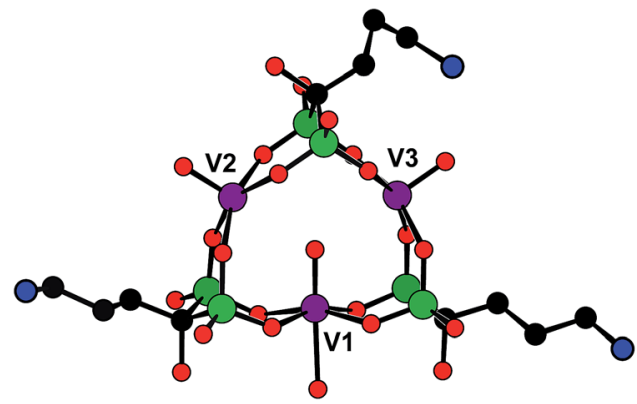

Fig. 1 Ball-and-stick representation of one of the molecules present in the structure of the $V_{3}(A l e)_{3}$ complex. Purple sphere $=V$, green spheres $=P$, black spheres $=C$, red spheres $=O$, blue spheres $=N ; H$ atoms are omitted for clarity.

$\left(\mathrm{V}_{3}(\mathrm{Zol})_{3}\right)$ previously characterized by some of us. ${ }^{44}$ In both $\mathrm{V}_{3}(\mathrm{Zol})_{3}$ and $\mathrm{V}_{3}(\mathrm{Ale})_{3}$, three $\mathrm{V}^{\mathrm{IV}}$ ions (bond valence sums for the vanadium ions in $\mathrm{V}_{3}$ (Ale $)_{3}=3.80-4.05$, Fig. S1, ESI $\dagger$ ) form an isosceles triangle, with the vanadium centers being in distorted octahedral environments. Three alendronate moieties occupy the edges of the triangle, acting as tetradentate ligands by connecting two by two the vanadium ions. Each vanadium center is connected to a terminal oxygen atom $\left(d_{\mathrm{V}=\mathrm{O}}=1.63-\right.$ $1.65 \AA$ ). Two of these $\mathrm{V}=\mathrm{O}$ bonds (V2 = O and V3 = O, Fig. 1) point to the outside of the molecule while the third one $(\mathrm{V} 1=\mathrm{O})$ points to the inside. Finally, the coordination sphere of the V1 atom is completed by a terminal water molecule while the V2 and $\mathrm{V} 3$ atoms are weakly bound to the $\mathrm{O}=\mathrm{V} 1$ oxygen atom $\left(d_{\mathrm{V}-}\right.$ $\mathrm{o}=2.76$ and $2.73 \AA$, respectively). Energy-dispersive X-ray (EDX) spectroscopy measurements are in agreement with a $\mathrm{P}: \mathrm{V}: \mathrm{Na}$ ratio of $6: 3: 3$ (ESI $\dagger$ ). This is confirmed by Inductively Coupled Plasma Atomic Emission Spectroscopy (ICP-OES), with a determined $\mathrm{P} / \mathrm{V}$ ratio of 2.04. Elemental analysis further confirms the proposed formula (Experimental section, ESI $\dagger$ ). The TGA curve (Fig. S2a, ESI $\dagger$ ) reveals three steps that can be attributed to water removal, ligand decomposition and finally formation of inorganic oxides (final experimental weight loss $41.0 \%$, calculated $39.0 \%$ ). Finally, the infrared spectrum of $\mathrm{POV}_{\text {red }}$ (Fig. S2b, $\mathrm{ESI} \dagger$ ) presents the characteristic bands of both the $\mathrm{P}-\mathrm{O} / \mathrm{P}=\mathrm{O}$ groups in the $1039-1086 \mathrm{~cm}^{-1}$ range and $\mathrm{P}-\mathrm{O}$ and $\mathrm{V}=\mathrm{O} / \mathrm{V}-\mathrm{O}$ groups in the 929-999 $\mathrm{cm}^{-1}$ range.

$\mathrm{POV}_{\text {red }}$ was then used to prepare in one step functionalized polyoxovanadate decorated gold nanoparticles. While reduced POVs have already been considered for the one pot preparation of metallic nanoparticles, ${ }^{\mathbf{4 5}, 46}$ it rapidly appeared that the nanoparticle synthesis protocol with the reported hybrid $\mathrm{POV}_{\text {red }}$ needed to be tailored. In order to prevent the $\mathrm{POV}_{\text {red }}$ denaturation, the synthesis was carried out by adding an aqueous solution of $\mathrm{HAuCl}_{4}$ basified to $\mathrm{pH}=6$ to an aqueous solution of $\mathrm{POV}_{\text {red }}$ at $\mathrm{pH}=6$. Indeed, the IR spectrum of the powder obtained by dissolution in water $\left(\mathrm{pH}\right.$ 6) of $\mathrm{POV}_{\text {red }}$ followed by the addition of ethanol is similar to that of $\operatorname{POV}_{\text {red }}$ (Fig. S2b, $\operatorname{ESI} \dagger$ ), strongly suggesting that the title complex is stable in this medium. Additionally, an excess of POM was used $(\gamma=$ $\left.\left[\mathrm{HAuCl}_{4}\right] /[\mathrm{POM}]=0.3\right)$ to ensure the total reduction of the $\mathrm{Au}^{\mathrm{III}}$ ions (see the ESI $\dagger$ for details). The colour change of the solution 
from turquoise to pink was indicative of the formation of the NPs@POV (POV being an oxidized form of the POV $\mathrm{red}_{\text {) gold }}$ nanoparticles, as confirmed by the presence of a surface plasmon resonance (SPR) band at $531 \mathrm{~nm}$ in the UV-spectra (Fig. 2a). In parallel, the CitNPs synthesized following the Turkevich method $^{47}$ and the $\mathrm{POV}_{\text {red }}$ functionalized citrate nanoparticles (CitNPs@POV ${ }_{\text {red}}$ ), prepared according to the procedure previously described ${ }^{48}$ for the grafting of Keggin polyoxotungstates, both show the expected narrow band centered at $520 \mathrm{~nm}$ characteristic of a particle size of $c a .15 \mathrm{~nm}$ (Fig. 2a). Note that the shift in the position of the SPR bands between the NPs@POV and CitNPs@POV ${ }_{\text {red }}$ is characteristic of the different sizes of the nanoparticles.

The size and dispersion of NPs@POV, CitNPs@POV ${ }_{\text {red }}$ and CitNPs were determined from Transmission Electron Microscopy (TEM) (Fig. 2b and S3, ESI $\dagger$ ) and Dynamic Light Scattering (DLS) analyses (Fig. 2c). TEM images revealed particle sizes of $30.8 \pm 9.4,15.1 \pm 1.9$ and $14.8 \pm 1.9 \mathrm{~nm}$ for NPs@POV, CitNPs@POV ${ }_{\text {red }}$, and CitNPs, respectively. As expected, the hydrodynamic diameter measured by DLS is larger for the three different batches of particles as it takes into account the presence of hydration layers, but also of POM layers for the two decorated NPs, not visible on TEM images. Besides, the zeta potential of CitNPs@POV ${ }_{\text {red }}(-49.6 \pm 1.7 \mathrm{mV})$ is lower than the zeta potential of pristine CitNPs $(-42.1 \pm 3.9 \mathrm{mV})$, which can be due to the adsorption at the surface of the NPs of the triply negatively charged POV. The zeta potential of NPs@POV (-44.1 $\pm 2.8 \mathrm{mV}$ ) is slightly less negative than for CitNPs@POV $\mathrm{Ped}_{\text {re }}$ This can be attributed to the oxidation of the $\mathrm{V}^{\mathrm{IV}}$ centers during the formation of the NPs@POV. Attenuated Total Reflectance Fourier Transform Infrared spectroscopy (ATR-FTIR) has also confirmed the presence of POVs at the surface of both NPs@POV and CitNPs@POV ${ }_{\text {red }}$, with the V-O vibrations related to the POV together with the $\mathrm{P}-\mathrm{O}$ vibrations and $\mathrm{NH}_{3}$ deformations related to the alendronate ligand being observed in the IR spectra (Fig. S4 and Table S1, ESI $\dagger$ ). ICP-OES allowed confirming the presence of $\mathrm{V}$ and $\mathrm{P}$ in stoichiometric proportions compared to the initial $\mathrm{POV}$, with a $\mathrm{P} / \mathrm{V}$ ratio equal to $2.0 \pm 0.1$ for NPs@POV and $1.9 \pm 0.1$ for CitNPs@POV ${ }_{\text {red. Moreover, }}$ taking into account the $\mathrm{Au} / \mathrm{V}$ ratio determined by ICP and the size of the NPs, the number of POV molecules per $\mathrm{nm}^{2}$ was estimated to be $38 \pm 8$ for the spherical $30.8 \mathrm{~nm}$ NPs@POV and $23 \pm 5$ for the $15.1 \mathrm{~nm}$ CitNPs@POV ${ }_{\text {red }}$ (see the ESI $\uparrow$ for details). We can note that the coverages are too high to correspond to a monolayer, which would lead to a maximum of 6 POV per $\mathrm{nm}^{2}$ (see the ESI $\dagger$ for details). Therefore, the ICP data clearly corroborate the presence of POV multilayers as previously discussed on the basis of DLS measurements.

\section{Inhibition of Gram-negative and Gram-positive bacteria biofilm growth by CitNPs, CitNPs@POV ${ }_{\text {red }}$ and NPs@POV}

The optical density method $\left(\mathrm{OD}_{620} \mathrm{~nm}\right)$ based on crystal violet staining was used to investigate the effect of CitNPs, CitNPs@POV ${ }_{\text {red }}$ and NPs@POV on P. aeruginosa ATCC® $27853^{\mathrm{TM}}$ and $S$. epidermidis CIP 105777 biofilm formation (see the ESI $\dagger$ for details). ${ }^{49}$ These Gram-negative and Gram-positive bacteria, respectively, represent an excellent model for biofilm growth inhibition studies as they have been shown to severely
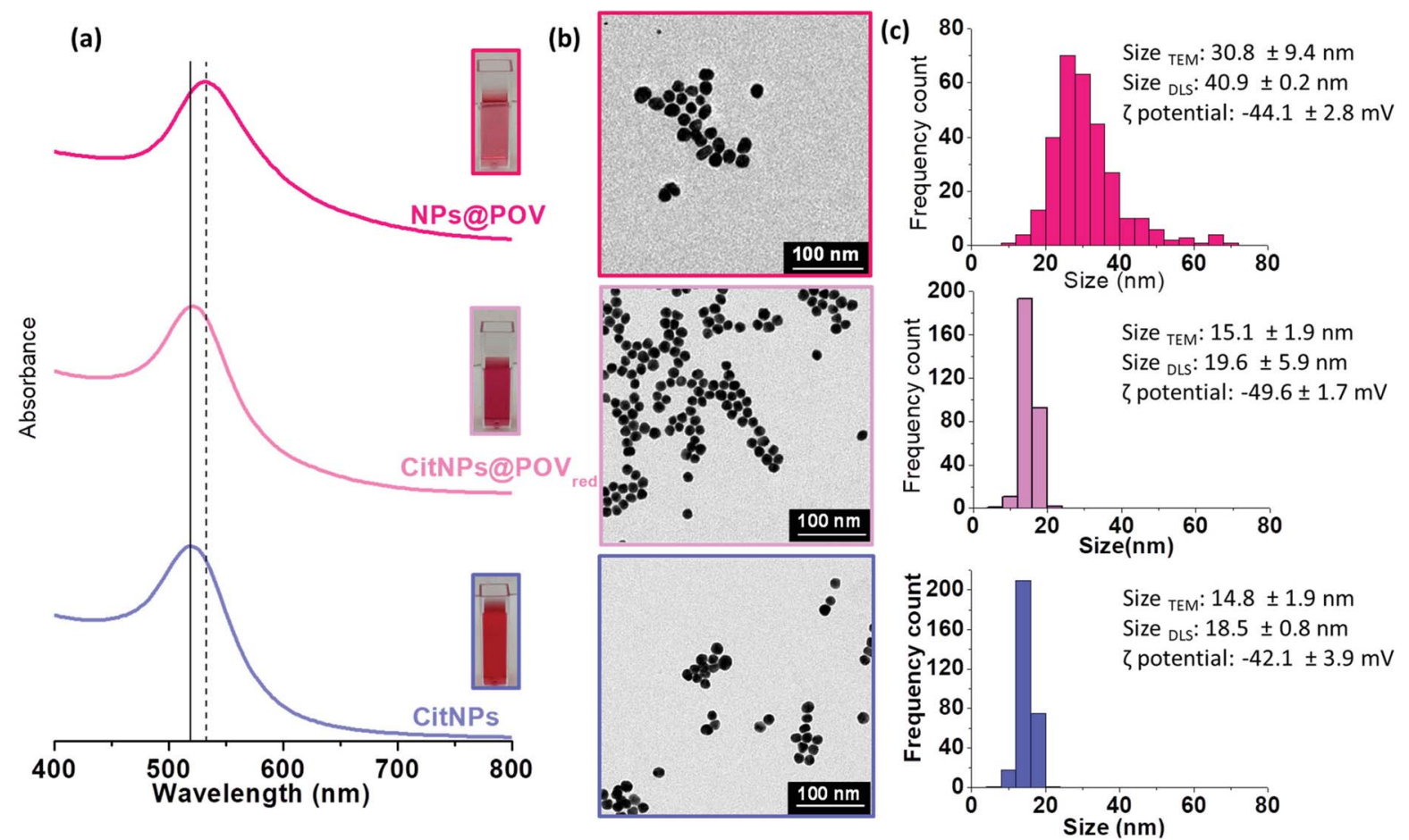

Fig. 2 Characterization of CitNPs, CitNPs@POV ${ }_{\text {red }}$ and NPs@POV. UV-vis spectra and colloidal suspension pictures (inset) (a), TEM images (b) and particle size distribution histograms and dynamic light scattering size and zeta potential values (c). 
develop on medical device surfaces, causing serious nosocomial infections. ${ }^{50-53}$ The biofilm formation was examined over periods of 24 and 48 hours (Fig. 3). The antibacterial activities of $\mathrm{POV}_{\text {red }}$ and alendronate at concentrations higher than those established for the functionalized NPs were also determined as references for the two different strains.

For $P$. aeruginosa, the bacterial growth was strongly inhibited after 24 hours of treatment by both NPs@POV and CitNPs@POV ${ }_{\text {red }}$, with a decrease of biofilm formation of $c a .60 \%$ compared to the control experiment. Noticeably, the biofilm growth inhibition is not significant for neither the unfunc-

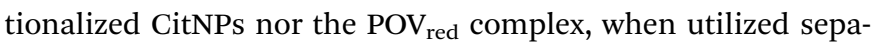
rately, highlighting a synergistic effect between the AuNPs and the POV. These results suggest that the gold nanoparticles could act as carriers to improve the penetration of the POV into the bacteria. This trend is confirmed after 48 hours of treatment, with a decrease of the biofilm formation of $c a .80 \%$ for

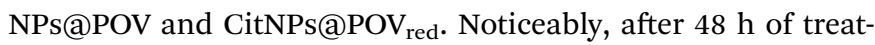
ment with alendronate and CitNPs, an antibacterial activity is observed as biofilm growth inhibition was around $60 \%$. However this antibacterial effect remains lower than the one observed for POV decorated nanoparticles, confirming the synergistic effect.

To investigate the possible influence of the particle size on the antibacterial activity, the inhibitory effects of citrate gold particles functionalized with POV red $_{\text {(CitNPs@POV }}$ red) with two different sizes (15 and $47 \mathrm{~nm}$ ) were investigated on $P$. aeruginosa. The synthesis and characterization of the $47 \mathrm{~nm}$ diameter AuNPs are described in the ESI (see the Experimental section and Fig. S5 $\dagger$ ). The antibacterial activities of the 15 and $47 \mathrm{~nm}$ NPs were found to be similar (Fig. S6†). Therefore, we can assume that the size of the nanoparticles cannot be regarded as a determining factor influencing the antibacterial activity.

Focusing now on $S$. epidermidis, Fig. 3b, it was observed that only the NPs@POV induce a significant decrease of the biofilm formation starting after $24 \mathrm{~h}$ of treatment, and, very interestingly, this effect is very strong $(>80 \%)$. The high antibacterial activity of the NPs@POV compared to the absence of activity of the CitNPs@POV ${ }_{\text {red }}$ against $S$. epidermidis can be tentatively attributed to the oxidation state of the vanadium centers $\left(\mathrm{V}^{\mathrm{IV}}\right.$ in CitNPs@POV ${ }_{\text {red }}$ and $V^{V}$ in NPs@POV). Finally, we can also note that the antibiofilm activity of the NPs@POV against S. epidermidis remains unchanged after an additional $24 \mathrm{~h}$.

The effect on the biofilm growth of the NPs@POV concentration in the 0.1-1 nM range was also studied for both strains (Fig. S7, ESI $\dagger$ ). For a concentration of $0.1 \mathrm{nM}$, a decrease of the $P$. aeruginosa biofilm formation of $50 \%$ after $24 \mathrm{~h}$ of treatment was observed, with no further evolution after $24 \mathrm{~h}$. At $0.2 \mathrm{nM}$, a decrease of $60 \%$ after $24 \mathrm{~h}$ and $80 \%$ after $48 \mathrm{~h}$ was determined, indicating that a $0.2 \mathrm{nM}$ concentration of NPs@POV is sufficient to obtain a strong antibacterial effect against this strain. Regarding S. epidermidis, a decrease of the biofilm formation of 40 and $70 \%$ upon 24 and 48 h of treatment, respectively, was observed for a concentration of $0.6 \mathrm{nM}$. The maximum antibacterial effect was found for a concentration of $1 \mathrm{nM}$, with $c a$. $80 \%$ inhibition of the biofilm formation after $24 \mathrm{~h}$.

In order to observe possible changes of the morphology of bacteria, scanning electron microscopy (SEM-FEG) micrographs of the $P$. aeruginosa and $S$. epidermidis were recorded after $24 \mathrm{~h}$ in the presence and in the absence of NPs@POV (Fig. S8, ESI $\dagger$ ). We used NPs@POV as an example as these hybrids show a good antibacterial activity against both bacterial strains.

\section{(a)}

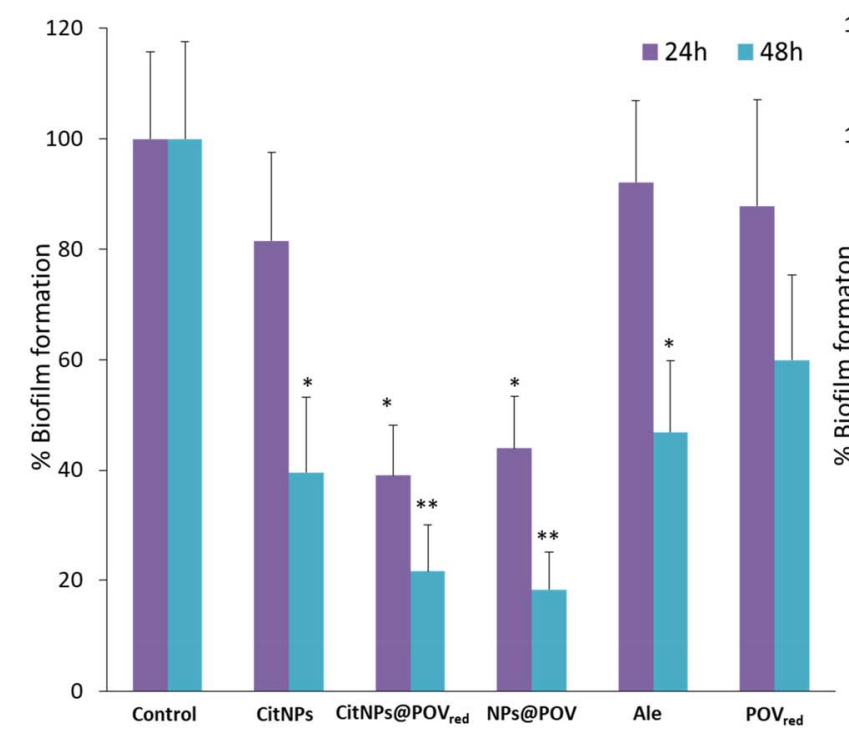

(b)

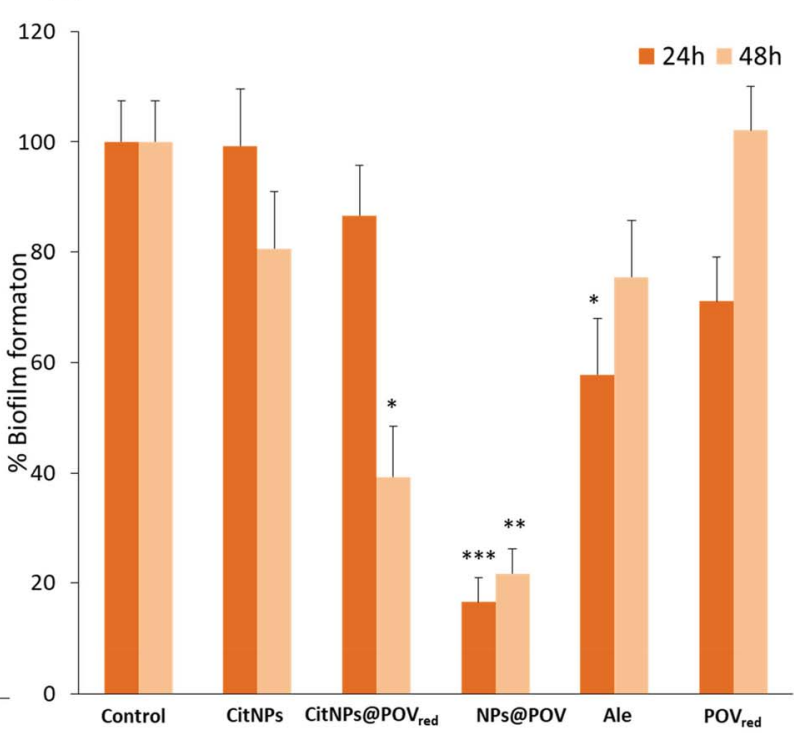

Fig. 3 The effect of CitNPs $(1.3 \mathrm{nM}), \mathrm{CitNPs}_{\mathrm{aPOV}}$ red $(1.3 \mathrm{nM}), \mathrm{NPs}(\mathrm{POV}(1.0 \mathrm{nM})$, alendronate $(540 \mu \mathrm{M})$, and POV red $(180 \mu \mathrm{M})$ on biofilm formation by (a) P. aeruginosa and (b) S. epidermidis after incubation for 24 and $48 \mathrm{~h}$ in 96 -well plates. The values of the experimental groups were compared with the control group. Statistical significance was analyzed by Students' $t$-test to detect the presence of statistically significant differences $(* * * p<0.001, * * p<0.01, * p<0.05)$. For CitNPs, CitNPs@POV red and NPs@POV the numbers in brackets correspond to the concentration of gold nanoparticles. 
The SEM images of the two bacterial strains without treatment showed intact bacterial membranes with $P$. aeruginosa exhibiting a rod like shape (Fig. S8a, ESI $\dagger$ ) and $S$. epidermidis exhibiting a spherical shape (Fig. S8c, ESI $\dagger$ ). In contrast, the cell envelopes of $P$. aeruginosa and $S$. epidermidis treated with NPs@POV are damaged and appear pierced causing the leakage of the cytoplasmic content and the collapse of the bacteria (Fig. S8b and d, ESI $\dagger$ ). From these results, it could be concluded that NPs@POV seriously affect the bacterial membrane integrity causing bacterial death. The exact antibacterial mechanism is, however, not well elucidated and will be investigated in future studies.

\section{Conclusions}

In conclusion, we have used a new reduced polyoxovanadate $\mathrm{V}_{3}(\mathrm{Ale})_{3}$ incorporating the biologically relevant alendronate ligand to prepare in one-pot, in water, at room temperature and in the absence of any additional surfactant the hybrid functionalized gold nanoparticles NPs@POV. The optimized synthetic protocol produced size-controlled monodisperse stable NPs. The POV $\mathrm{P}_{\text {red }}$ thus acts as a reducing agent but also as capping agent to stabilise the nanoparticles. The nanocomposites were thoroughly characterized by TGA, ATR-FTIR, UV-Vis, DLS, TEM, EDX and elemental analysis experiments. The high antibiofilm activity of NPs@POV towards both the Gram-negative and Gram-positive resistant bacteria was evidenced. Importantly, comparative studies strongly suggest that the three components constituting the NPs@POV $\left(\mathrm{Au}^{0}\right.$ core, vanadium and alendronate) act synergistically. The activity of $\mathrm{POV}_{\text {red }}$ functionalized citrate gold nanoparticles, CitNPs@POV ${ }_{\text {red }}$, was also studied, allowing us to conclude that the oxidation state of the vanadium centers constituting the POM may play a significant role in the inhibition of Gram-positive bacteria biofilm growth. This work, which to the best of our knowledge represents the first investigation of POMfunctionalized NPs for antibiofilm applications, opens the way to a new generation of antibiofilm agents. We are currently investigating the influence of the nature of the polyoxometalate on the biological properties of such nanocomposites. Also, an advantage of alendronate is that it can be easily functionalized via its amino group. We are thus also presently working on the elaboration and the investigation of the inhibition of biofilm growth activity of antibiotic/alendronate/polyoxometalate NP systems.

\section{Conflicts of interest}

There are no conflicts to declare.

\section{Acknowledgements}

This work was supported by the Ministère de l'Enseignement Supérieur et de la Recherche, the CNRS, the Université de Versailles Saint Quentin en Yvelines and a public grant overseen by the French National Research Agency (ANR) as part of the "Investissements d'Avenir" program no. ANR-11-IDEX-0003-02 and CHARMMMAT ANR-11-LABX-0039.

\section{Notes and references}

1 P. V. Baptista, M. P. McCusker, A. Carvalho, D. A. Ferreira, N. M. Mohan, M. Martins and A. R. Fernandes, Front. Microbiol., 2018, 9, 1-26.

2 L. Hall-Stoodley, J. W. Costerton and P. Stoodley, Nat. Rev. Microbiol., 2004, 2, 95-108.

3 D. Davies, Nat. Rev. Drug Discovery, 2003, 2, 114-122.

4 P. S. Stewart and J. W. Costerton, Lancet, 2001, 358, 135-138.

5 G. R. Rudramurthy, M. K. Swamy, U. R. Sinniah and A. Ghasemzadeh, Molecules, 2016, 21, 1-30.

6 C. W. Chen, C. Y. Hsu, S. M. Lai, W. J. Syu, T. Y. Wang and P. S. Lai, Adv. Drug Delivery Rev., 2014, 78, 88-104.

7 J. Conde, M. Larguinho, A. Cordeiro, L. R. Raposo, P. M. Costa, S. Santos, M. S. Diniz, A. R. Fernandes and P. V. Baptista, Nanotoxicology, 2014, 8, 521-532.

8 X. Li, S. M. Robinson, A. Gupta, K. Saha, Z. Jiang, D. F. Moyano, A. Sahar, M. A. Riley and V. M. Rotello, ACS Nano, 2014, 8, 10682-10686.

9 U. Rajchakit and V. Sarojini, Bioconjugate Chem., 2017, 28, 2673-2686.

10 Y. Zhao and X. Jiang, Nanoscale, 2013, 5, 8340-8350.

11 M. Rai, A. P. Ingle, R. Pandit, P. Paralikar, I. Gupta, M. V. Chaud and C. A. dos Santos, Int. J. Pharm., 2017, 532, 139-148.

12 A. N. Brown, K. Smith, T. A. Samuels, J. Lu, S. O. Obare and M. E. Scott, Appl. Environ. Microbiol., 2012, 78, 2768-2774.

13 T. Roshmi, K. R. Soumya, M. Jyothis and E. K. Radhakrishnan, Gold Bull., 2015, 48, 63-71.

14 H. Mu, J. Tang, Q. Liu, C. Sun, T. Wang and J. Duan, Sci. Rep., 2016, 6, 1-9.

15 G. Vinoj, R. Pati, A. Sonawane and B. Vaseeharan, Antimicrob. Agents Chemother., 2015, 59, 763-771.

16 Q. Yu, J. Li, Y. Zhang, Y. Wang, L. Liu and M. Li, Sci. Rep., 2016, 6, 1-14.

17 M. Ramasamy, J. H. Lee and J. Lee, Colloids Surf., B, 2017, 160, 639-648.

18 X. Zhao, Y. Jia, J. Li, R. Dong, J. Zhang, C. Ma, H. Wang, Y. Rui and X. Jiang, ACS Appl. Mater. Interfaces, 2018, 10, 29398-29406.

19 Y. Feng, W. Chen, Y. Jia, Y. Tian, Y. Zhao, F. Long, Y. Rui and X. Jiang, Nanoscale, 2016, 8, 13223-13227.

20 A. Dolbecq, E. Dumas, C. R. Mayer and P. Mialane, Chem. Rev., 2010, 110, 6009-6048.

21 A. Bijelic, M. Aureliano and A. Rompel, Chem. Commun., 2018, 54, 1153-1169.

22 N. I. Gumerova, E. Al-Sayed, L. Krivosudský, H. ČipčićPaljetak, D. Verbanac and A. Rompel, Front. Chem., 2018, 6, 1-9.

23 T. Yamase, J. Mater. Chem., 2005, 15, 4773.

24 A. Kubo, L. Kremer, S. Herrmann, S. G. Mitchell, O. M. Bondarenko, A. Kahru and C. Streb, ChemPlusChem, 2017, 10130, 867-871.

25 P. Yang, B. S. Bassil, Z. Lin, A. Haider, G. Alfaro-Espinoza, M. S. Ullrich, C. Silvestru and U. Kortz, Chem.-Eur. J., 2015, 21, 15600-15606. 
26 P. Yang, Z. Lin, G. Alfaro-Espinoza, M. S. Ullrich, C. I. Raţ, C. Silvestru and U. Kortz, Inorg. Chem., 2016, 55, 251-258.

27 A. Misra, I. Franco Castillo, D. P. Müller, C. González, S. Eyssautier-Chuine, A. Ziegler, J. M. de la Fuente, S. G. Mitchell and C. Streb, Angew. Chem., Int. Ed., 2018, 57, 14926-14931.

28 R. H. Piva, M. C. Rocha, D. H. Piva, H. Imasato, I. Malavazi and U. P. Rodrigues-Filho, ACS Appl. Mater. Interfaces, 2018, 10, 30963-30972.

29 H. K. Daima, P. R. Selvakannan, A. E. Kandjani, R. Shukla, S. K. Bhargavaa and V. Bansal, Nanoscale, 2014, 6, 758-765.

30 H. K. Daima, P. R. Selvakannan, R. Shukla, S. K. Bhargava and V. Bansal, PLoS One, 2013, 8, 1-14.

31 A. Dolbecq, J. D. Compain, P. Mialane, J. Marrot, F. Sécheresse, B. Keita, L. R. B. Holzle, F. Miserque and L. Nadjo, Chem.-Eur. J., 2009, 15, 733-741.

32 G. Zhang, B. Keita, R. N. Biboum, F. Miserque, P. Berthet, A. Dolbecq, P. Mialane, L. Catala and L. Nadjo, J. Mater. Chem., 2009, 19, 8639-8644.

33 U. Jameel, M. Zhu, X. Chen and Z. Tong, J. Mater. Sci., 2016, 51, 2181-2198.

34 R. Ban, X. Sun, J. Wang, P. Ma, C. Zhang, J. Niu and J. Wang, Dalton Trans., 2017, 46, 5856-5863.

35 L. Yang, Z. Zhou, J. Wang and J. Niu, Cryst. Growth Des., 2013, 4, 2540-2547.

36 A. Banerjee, F. S. Raad, N. Vankova, B. S. Bassil, T. Heine and U. Kortz, Inorg. Chem., 2011, 50, 11667-11675.

37 U. Kortz, G. B. Jameson and M. T. Pope, J. Am. Chem. Soc., 1994, 116, 2659-2660.

38 A. Banerjee, B. S. Bassil, G. V. Röschenthaler and U. Kortz, Chem. Soc. Rev., 2012, 41, 7590-7604.

39 A. Saad, W. Zhu, G. Rousseau, P. Mialane, J. Marrot, M. Haouas, F. Taulelle, R. Dessapt, H. Serier-Brault,
E. Rivière, T. Kubo, E. Oldfield and A. Dolbecq, Chem.-Eur. J., 2015, 21, 10537-10547.

40 C. Peloux, P. Mialane and A. Dolbecq, Angew. Chem., Int. Ed., 2002, 542, 2808-2810.

41 J. D. Compain, P. Mialane, J. Marrot, F. Sécheresse, W. Zhu, E. Oldfield and A. Dolbecq, Chem.-Eur. J., 2010, 16, 1374113748.

42 A. K. Hiltunen, M. E. Skogman, K. Rosenqvist, H. Juvonen, P. Ihalainen, J. Peltonen, A. Juppo and A. Fallarero, Int. J. Pharm., 2016, 501, 211-220.

43 Y. Wang and I. A. Weinstock, Chem. Soc. Rev., 2012, 41, 74797496.

44 H. El Moll, W. Zhu, E. Oldfield, L. M. Rodriguez-Albelo, P. Mialane, J. Marrot, N. Vila, I. M. Mbomekallé, E. Rivière, C. Duboc and A. Dolbecq, Inorg. Chem., 2012, 51, 7921-7931.

45 Y. Y. Bao, L. H. Bi and L. X. Wu, J. Solid State Chem., 2011, 184, 546-556.

46 R. Liu, S. Li, X. Yu, G. Zhang, S. Zhang, J. Yao, B. Keita, L. Nadjo and L. Zhi, Small, 2012, 8, 1398-1406.

47 J. Tukevich, P. C. Stevenson and J. Hillier, Discuss. Faraday Soc., 1951, 11, 55-75.

48 Y. Wang, A. Neyman, E. Arkhangelsky, V. Gitis, L. Meshi and I. A. Weinstock, J. Am. Chem. Soc., 2009, 131, 17412-17422.

49 H. Mu, A. Zhang, L. Zhang, H. Niu and J. Duan, Food Control, 2014, 38, 215-220.

50 K. Niemirowicz, I. Swiecicka, A. Z. Wilczewska, I. Misztalewska, B. Kalska-Szostko, K. Bienias, R. Bucki and H. Car, Int. J. Nanomed., 2014, 9, 2217-2224.

51 M. Klausen, A. Heydorn, P. Ragas, L. Lambertsen, A. AaesJørgensen, S. Molin and T. Tolker-Nielsen, Mol. Microbiol., 2003, 48, 1511-1524.

52 F. Barbier and M. Wolff, Med. Sci., 2010, 26, 960-968.

53 M. Otto, Nat. Rev. Microbiol., 2009, 7, 555-567. 